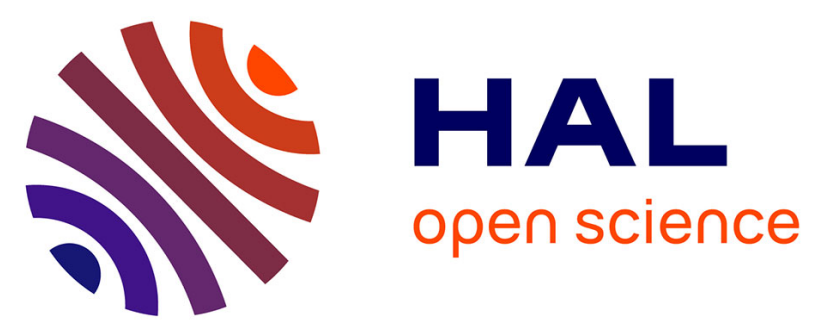

\title{
Evaluation of the FlowCapt Acoustic Sensor for the Aeolian Transport of Snow
}

\author{
Alexandre Trouvilliez, F. Naaim-Bouvet, Hervé Bellot, Christophe Genthon, \\ Hubert Gallée
}

\section{To cite this version:}

Alexandre Trouvilliez, F. Naaim-Bouvet, Hervé Bellot, Christophe Genthon, Hubert Gallée. Evaluation of the FlowCapt Acoustic Sensor for the Aeolian Transport of Snow. Journal of Atmospheric and Oceanic Technology, 2015, 32 (9), pp.1630-1641. 10.1175/JTECH-D-14-00104.1 . insu-01235633

\section{HAL Id: insu-01235633 \\ https://hal-insu.archives-ouvertes.fr/insu-01235633}

Submitted on 30 Nov 2015

HAL is a multi-disciplinary open access archive for the deposit and dissemination of scientific research documents, whether they are published or not. The documents may come from teaching and research institutions in France or abroad, or from public or private research centers.
L'archive ouverte pluridisciplinaire HAL, est destinée au dépôt et à la diffusion de documents scientifiques de niveau recherche, publiés ou non, émanant des établissements d'enseignement et de recherche français ou étrangers, des laboratoires publics ou privés. 


\title{
${ }^{\ominus}$ Evaluation of the FlowCapt Acoustic Sensor for the Aeolian Transport of Snow
}

\author{
AlEXANDRE TROUVILLIEZ \\ LGGE, UMR 5183, CNRS, and UR ETNA, Irstea, Saint-Martin-d'Hères, and DTecEMF, Cerema, LGCE, Plouzané, \\ and Université Grenoble Alpes, Grenoble, France \\ Florence NAAim-Bouvet AND Hervé Bellot \\ UR ETNA, Irstea, Saint-Martin-d'Hères, and Université Grenoble Alpes, Grenoble, France \\ Christophe Genthon AND Hubert Gallée \\ LGGE, UMR 5183, CNRS, Saint-Martin d'Hères, France
}

(Manuscript received 19 May 2014, in final form 13 April 2015)

\begin{abstract}
FlowCapt acoustic sensors, designed for measuring the aeolian transport of snow fluxes, are compared to the snow particle counter S7optical sensor, considered herein as the reference. They were compared in the French Alps at the Lac Blanc Pass, where a bench test for the aeolian transport of snow was set up. The two existing generations of FlowCapt are compared. Both seem to be good detectors for the aeolian transport of snow, especially for transport events with a flux above $1 \mathrm{~g} \mathrm{~m}^{-2} \mathrm{~s}^{-1}$. The second-generation FlowCapt is also compared in terms of quantification. The aeolian snow mass fluxes and snow quantity transported recorded by the secondgeneration FlowCapt are close to the integrative snow particle counter S7 fluxes for an event without precipitation, but they are underestimated when an event with precipitation is considered. When the winter season is considered, for integrative snow particle counter S7 fluxes above $20 \mathrm{~g} \mathrm{~m}^{-2} \mathrm{~s}^{-1}$, the second-generation FlowCapt fluxes are underestimated, regardless of precipitation. In conclusion, both generations of FlowCapt can be used as a drifting snow detector and the second generation can record an underestimation of the quantity of snow transported at one location: over the winter season, the quantity of snow transported recorded by the SPC is between 4 and 6 times greater than the quantity recorded by the second-generation FlowCapt.
\end{abstract}

\section{Introduction}

The aeolian transport of snow is frequent in cold windy areas such as mountainous and polar regions. In mountainous regions, this transport is one of the sources of avalanche risk by loading in the release areas and is also responsible for infrastructure and road maintenance problems. In polar regions, the wind transport of snow has a significant impact on the surface mass balance by redistributing precipitation, snow exported outside the ice shelf, snow particle sublimation, and

¿ Denotes Open Access content.

Corresponding author address: Alexandre Trouvilliez, DTecEMF, Cerema, Technopôle Brest Iroise BP 5, 155 Rue Pierre Bouguer, 29280 Plouzané, France.

E-mail: alexandre.trouvilliez@cerema.fr changes in the albedo. It is the main ablation process in Antarctica, where strong katabatic winds are associated with frequent and intense transport of snow by the wind (Lenaerts et al. 2012). Therefore, the duration and intensity of the transport events require characterization.

Since no standard in the aeolian process measurements exists, it is difficult to compare measurements taken in different regions (Barchyn et al. 2011). Moreover, a wide variety of instruments is used, with mechanical (Budd et al. 1966), optical (Wendler 1989), piezoelectric (Tüg 1988), and acoustic (Chritin et al. 1999) techniques. The measurement capacities of these sensors are often not assessed. In Antarctica, because of significant environmental and technical constraints, few reliable instruments may be used and data are few and far between. It is therefore important to know the reliability of the sensors used, so as not to overinterpret the results.

One of the instruments used in research campaigns and in road management is the FlowCapt. It is a 
commercialized acoustic sensor able to quantify the horizontal snow flux with an accuracy given by the manufacturer of $\pm 5 \%$ (Chritin et al. 1999). This instrument has been used in different research campaigns in the Swiss and French Alps (Lehning and Fierz 2008; Naaim-Bouvet et al. 2010), in the Arctic region (Jaedicke 2002; Savelyev et al. 2006), and in Antarctica (Scarchilli et al. 2010; Gallée et al. 2013). Two successive versions of FlowCapt exist: one, referred to as the firstgeneration FlowCapt, was sold until 2009; and the second one, referred to as the second-generation FlowCapt, has been sold since 2009 .

The first-generation instrument was first tested during a field season in Spitsbergen, but measurement accuracy was not evaluated in comparison with other instruments (Jaedicke 2001). The first evaluation comparing different mechanical snow traps and optical particle counters was carried out in a climatic wind tunnel and in the field: for artificial snow, the first-generation FlowCapt consistently underestimated the snow mass fluxes measured by the mechanical traps (Lehning et al. 2002). In the field, large overestimations of the snow mass flux resulted in high snow densities and temperatures close to the melting point, whereas at cold temperatures and low densities, the fluxes were underestimated. An overestimation of one order of magnitude was also noted by Savelyev et al. (2006) for a comparison with nets in the Arctic. Cierco et al. (2007) proposed a new calibration of the instrument as the result of his own intercomparison with nets in a wind tunnel (with corn cobs and sand) and in the field (with snow) in the French Alps showing substantial flux overestimation. The second-generation instrument has never been evaluated.

This paper compares the second-generation FlowCapt and the snow particle counter S7 in the field in terms of event detection and snow mass flux quantification and the first-generation FlowCapt only in terms of event detection. The wind speed, which is a sensor output, is also investigated. The aim is to evaluate the two generations in field conditions considering the FlowCapt as a black box. The next section presents the test site and the instruments used. The data and the methods used in the comparison are described in section 3. Section 4 describes the results on wind speed, event detection, and aeolian snow mass flux quantification. Finally, the discussion and concluding remarks will be presented in the last section.

\section{Instruments and test site}

The FlowCapt is described in detail in Chritin et al. (1999) and Cierco et al. (2007). It consists of a hollow tube fitted with electroacoustic transducers. The detection principle is based on the acoustic pressure generated by the impact of particles with the tube. The acoustic pressure is converted into an electrical output signal. It also outputs an estimation of wind velocity, based on an analysis of the noise created by turbulence. To distinguish between noise from snow particles and air turbulence, the signal-processing algorithm uses spectral analysis. Wind creates a signal with a lower frequency than the impacts of particles on the tube. The tube is coated to prevent riming. The sensor is available as a single-tube instrument, giving an integrated mass flux over the length of the tube, which can vary from 0.3 to $1 \mathrm{~m}$. FlowCapt is offered with a complete calibration, providing the snow mass flux:

$$
\mu_{\mathrm{mc}}=A \times \operatorname{signal}^{B},
$$

where $\mu_{\mathrm{mc}}$ is the snow mass flux with the manufacturer's calibration $\left(\mathrm{g} \mathrm{m}^{-2} \mathrm{~s}^{-1}\right)$, signal, the amplified and filtered signal of the particle impacts $(\mathrm{mV})$, and two constants $(A, B)$ that depend on the calibration procedure using the controlled flux of polyvinyl chloride (PVC) particles. For $B$, both generations have a fixed value of 2 . The FlowCapt is based on the momentum transfer of individual snow particles to the sensitive surface, such as the piezoelectric surfaces, which means that the acoustic pressure depends on the size, the density, and the speed of the particle. Cierco et al. (2007) noted different responses depending on the type of particle.

Changes in the second-generation instrument concern the hardware: new electroacoustic transducers, a new type of tube coating, and a new suspension of the microphone to avoid noise from the vibration generated by the wind. The calibration procedure remains the same but is now individual for each sensor [each sensor has a specific $A$ constant in Eq. (1); V. Chritin 2010, personal communication].

The second instrument used for the intercomparison is the snow particle counter S7 (SPC-S7). The sensor is described in detail in Sato et al. (1993). The technique is based on the strong absorption of the infrared light by the snow. The diameter and the number of blowing snow particles are detected by their shadows on a photodiode. Electric pulse signals of the snow particles passing through a sampling volume $(2 \mathrm{~mm} \times 25 \mathrm{~mm} \times 0.5 \mathrm{~mm})$ are sent to an analyzing logger. In this way, the SPC detects particles between 40 and $500 \mu \mathrm{m}$ in mean diameter. It divides them into 32 classes and records the particle number every $1 \mathrm{~s}$. The SPC has a self-steering wind vane. The sampling area, perpendicular to the horizontal wind vector, is $50 \mathrm{~mm}^{2}(2 \mathrm{~mm} \times 25 \mathrm{~mm})$. If the diameter of a snow particle is larger than the maximum diameter class, then the snow particle is considered to belong to the maximum diameter class. The 
horizontal snow mass flux $\mu_{\mathrm{SPC}}$ is calculated as follows (Naaim-Bouvet et al. 2014):

$$
\mu_{\mathrm{SPC}}=\sum_{i=1}^{32} \mu_{\mathrm{SPC} i}=\sum_{i=1}^{32} \frac{n_{i} S_{i} \frac{4}{3} \pi\left(\frac{d_{p i}}{2}\right)^{3} \rho_{p i}}{S_{\mathrm{SPC}} \times t},
$$

where $\mu_{\mathrm{SPC}}$ is the flux of the $\mathrm{SPC}\left(\mathrm{g} \mathrm{m}^{-2} \mathrm{~s}^{-1}\right)$ and $\mu_{\mathrm{SPC} i}$ is the horizontal snow mass flux for the diameter $i$. Term $n_{i}$ is the number of drifting snow particles of the $i$ th class, and $S_{i}$ is the shape factor of snow particles of the $i$ th class, which is the ratio of a spherical cubic volume to the snow particle cubic volume. Term $d_{p i}$ is the mean diameter of the diameter class $i(\mathrm{~m}), \rho_{p i}$ is the particle density in the class $i\left(\mathrm{~g} \mathrm{~m}^{-3}\right), S_{\mathrm{SPC}}$ is the sample area of the SPC (m), and $t$ is the sample period (s). As usual, the snow particles blow as individual grains, not snowflakes. Thus the particle density is set to the ice density and is equal to $917 \mathrm{~kg} \mathrm{~m}^{-3}$. In this study $S_{i}$ is equal to 1 , assuming spherical snow particles. Sato et al. (2005) estimate the theoretical snow mass flux values with different particle shapes. It was shown and confirmed by experiments that the mass flux tends to be overestimated by the SPC-S7 as the degree of nonsphericity increases for spheroidlike particles and when square-pillar-like particles become thinner or elongated. To take this effect into account, a formulation for $S_{i}$ has been proposed (Sato et al. 2005).

The SPC has been compared to measurements with nets, described in Takeuchi (1980). Both fluxes recorded by the two instruments agree considerably for fluxes close to the surface $(<0.5 \mathrm{~m})$ and with wind speed below $12 \mathrm{~m} \mathrm{~s}^{-1}$ (Sato et al. 1993). The SPC has also been compared to two types of nets in a climatic wind tunnel. The flux value between the three types of instruments gave comparable results (Lehning et al. 2002). An intercomparison in the French Alps between the SPC and butterfly nets drew the same conclusion as the previous intercomparison (Naaim-Bouvet et al. 2010). The SPC will be used preferably for the comparison rather than nets because the FlowCapt flux can then be compared on the same time frequency over the whole winter season. The previous comparison between nets and the SPC gave confidence in the SPC measurements, so it will be used here as a reference compared with the FlowCapt measurements.

The intercomparison was conducted at Lac Blanc Pass during winter 2011/12. The field is located at the Alpe d'Huez ski resort near Grenoble, France. The large pass aligned perpendicular to the north-south direction has been dedicated to aeolian snow transport for approximately 20 years and snowdrift sensors have been compared there many times (Michaux et al. 2001; Cierco et al. 2007; Naaim-Bouvet et al. 2010; Bellot et al. 2011) and model evaluations have been carried out (Vionnet et al. 2013). The area consists of a relatively flat terrain (about $25000 \mathrm{~m}^{2}$ ). The pass orientation and the specific configuration of the surrounding summits make it closely resemble a natural wind tunnel (Fig. 1): the north-south direction accounts for $90 \%$ of the wind directions. Aeolian snow transport is observed $10 \%$ of the time in winter and occurs with concurrent snowfall $37 \%$ of the time (Vionnet et al. 2013). The experimental site is described in detail in Naaim-Bouvet et al. (2010) with the changes in the instrument setup over the years.

During winter 2011/12, the site was equipped with several vertical masts aligned perpendicularly in the north-south direction to ensure the fewest possible interactions between the instruments (Fig. 2). Three SPCs were aligned vertically; the higher SPC, noted SPC3, was fixed and cannot move during the season, whereas the middle and the lower SPCs, noted SPC2 and SPC1, respectively, were set up on a vertically movable rack, which ensures a constant distance between them and an adjustable height from the surface to prevent them from being buried. Right above the SPCs, an optical snow depth sensor (Jenoptik SHM30) provides the surface elevation, which measures the snow depth at the exact position of the SPCs: the beam diameter of the laser was approximately $7 \mathrm{~mm}$ at the snow surface. A 1-m secondgeneration FlowCapt was installed vertically on the same rack as the lower SPCs (SPC1 and SPC2), with the lower part of the tube at the same height as SPC1 and thus the higher part of the tube at the same height as the SPC2. SPC1, SPC2, and the 1-m second-generation FlowCapts are bound together, so that they keep their relation in height when they are moved to prevent them from being buried. Six 0.3-m first-generation FlowCapts were set up vertically $10 \mathrm{~m}$ from the SPCs with a fixed height. Only one of them was used in this intercomparison, the fourth from the surface, because it was not entirely buried and was less sensitive to vibration than the higher one, as highlighted by Cierco et al. (2007), and the fifth from the surface was malfunctioning. Two cup anemometers were mounted right next to SPC1 and SPC2 and at the same height above the snow surface. The instruments do not have the same acquisition frequency. The lower sampling rate came from FlowCapt data that had to be averaged over $10 \mathrm{~min}$. Thus, the intercomparison will be based on 10-min means. Additionally, a $10-\mathrm{m}$ mast is located $60 \mathrm{~m}$ from the SPC mast perpendicular to the north-south direction. Platinum resistance thermometers took temperature measurements inside ventilated radiative shields 2 and $8 \mathrm{~m}$ in height. 


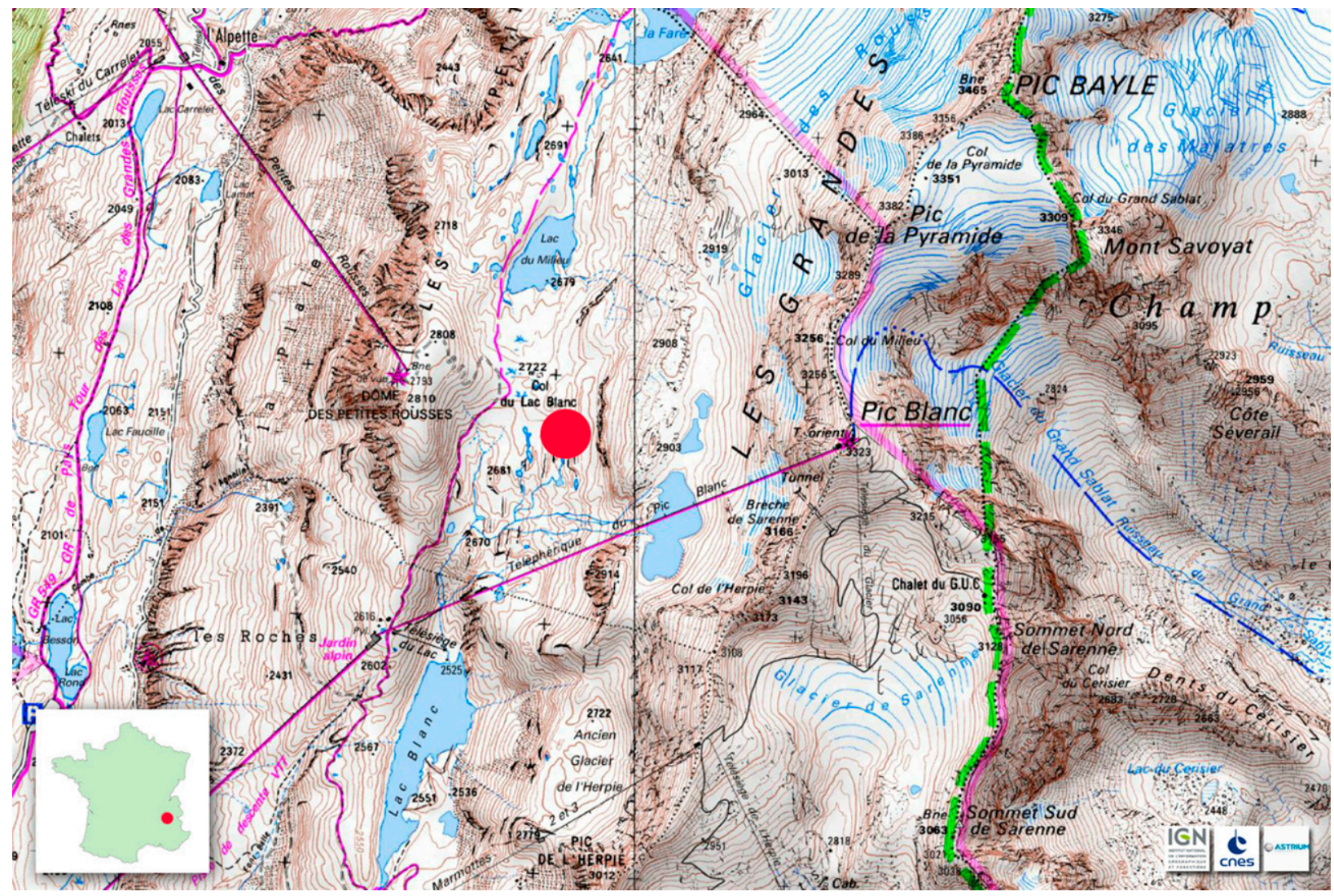

FIG. 1. The aeolian snow transport workbench location (red dot) in the Lac Blanc Pass (scale: 1:14000, adapted from http://www. geoportail.gouv.fr/accueil). (inset) Lac Blanc Pass location in France.

One of the main uncertainties rises from the local differences in surface elevation between the SPCs and the FlowCapt. To characterize this uncertainty, the difference in height between the lower SPC and the lower part of the second-generation FlowCapt was monitored weekly. The difference can be up to $8 \mathrm{~cm}$ due to the presence of sastrugi. Therefore, we assumed afterward that the lower part of the second-generation FlowCapt was at the same height as the SPC1 $\pm 8 \mathrm{~cm}$. The same hypothesis was applied to the height of the

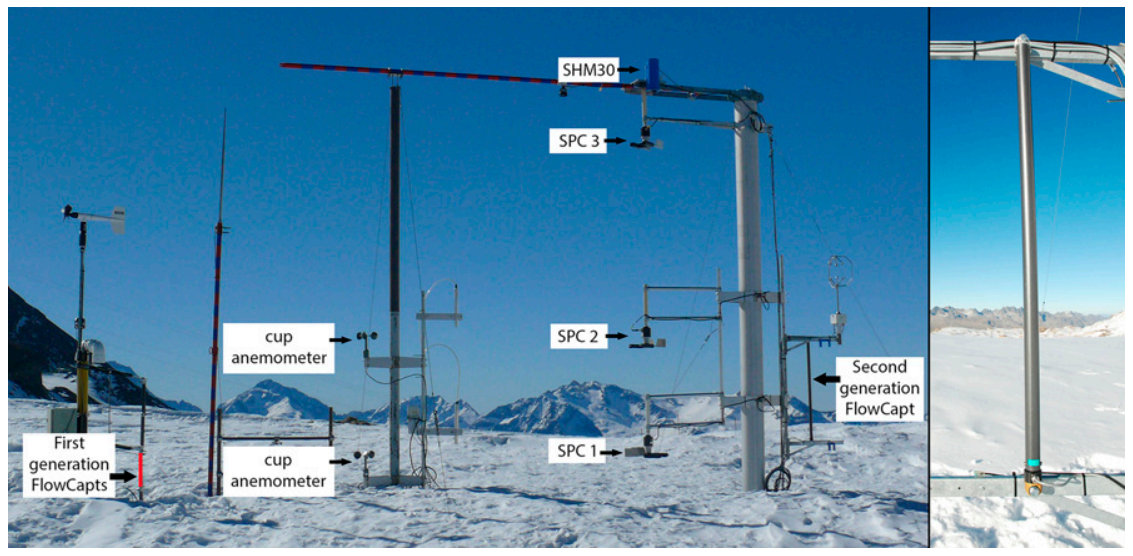

FIG. 2. (left) Experimental bench on the aeolian transport of snow at Lac Blanc Pass during winter 2011/12. FlowCapt_2G used in the evaluation is highlighted in red. (right) Picture of the 1-m FlowCapt_2G used for the evaluation. 
first-generation FlowCapt, which was the height determined by the snow depth sensor $\pm 8 \mathrm{~cm}$.

\section{Data and methods}

\section{a. Wind speed}

By construction, the FlowCapt wind speed value is a mean velocity integrated over $1 \mathrm{~m}$ :

$$
\overline{u_{\text {int }}}=\frac{1}{H_{h}-H_{l}} \int_{H_{l}}^{H_{h}} \overline{u(z)} d z,
$$

where $\overline{u_{\text {int }}}$ is the integrated wind speed $\left(\mathrm{m} \mathrm{s}^{-1}\right) ; H_{h}$ and $H_{1}$ are the higher and the lower heights of the FlowCapt, respectively; and $\overline{u(z)}$ is the mean wind speed $\left(\mathrm{m} \mathrm{s}^{-1}\right)$ at the height $z$. Term $\overline{u_{\text {int }}}$ can be calculated from the two cup anemometers, considering that the average turbulent wind speed profile over a relatively smooth surface such as snow can be approximated using a logarithmic profile:

$$
u(z)=\frac{u_{*}}{k} \ln \left(\frac{z}{z_{0}}\right)
$$

where $u_{*}$ is the friction velocity $\left(\mathrm{m} \mathrm{s}^{-1}\right), k$ is the von Kármán constant, and $z_{0}$ is the roughness length $(\mathrm{m})$. The profile method (Garratt 1992) using the two cup anemometers was used to calculate the integrated wind speed over the second-generation FlowCapt height. This method is valid under neutral stability conditions of the atmosphere and assumes that measurements are averaged over a long enough period to describe turbulence as steady state and homogenous (Stull 1988). Only 10-min wind speeds with a near-neutral stratification of the atmosphere (temperature gradient $<0.01^{\circ} \mathrm{m}^{-1}$ ) determined by the $10-\mathrm{m}$ mast were used in the wind speed evaluation.

\section{b. Event detection}

First- and second-generation FlowCapts have a $0.001 \mathrm{~g} \mathrm{~m}^{-2} \mathrm{~s}^{-1}$ flux threshold, whereas the SPC has a lower threshold. For the comparison, the event threshold for the SPCs was fixed at $0.001 \mathrm{~g} \mathrm{~m}^{-2} \mathrm{~s}^{-1}$. For transport detection, two cases were distinguished as a function of the occurrence of precipitation. The first case was when snow particles were only lifted from the ground by the wind (aeolian snow transport without precipitation). In this case, the SPC1 and the secondgeneration FlowCapt (FlowCapt_2G) should detect a flux at the same time as the lower part of the sensitive surface of the FlowCapt_2G was at the same height as the SPC1. For the first-generation FlowCapt (FlowCapt_1G), the lower part of the sensitive surface was always located below the SPC1 height: The height of the bottom end of the FlowCapt_1G was $25 \mathrm{~cm}$ below SPC1; the FlowCapt_1G was sometimes buried but at least two-thirds of the sensitive surface was always exposed to the atmosphere. Consequently, it may have detected the beginning of the transport event or events very close to the surface that the SPC1 did not detect. The second case is when an aeolian snow transport with precipitation occurs; the three sensors should detect a mass flux at the same time, because particles are present at all the heights considered regardless of the wind speed. Thus, the event detection will be conducted between the first- and second-generation FlowCapt and the SPC1 with a $0.001 \mathrm{~g} \mathrm{~m}^{-2} \mathrm{~s}^{-1}$ threshold on a 10 -min basis.

\section{c. Snow mass fluxes}

As for the wind speed, the FlowCapt flux was integrated throughout the height, whereas the SPC had a single value. To compare the FlowCapt with the SPCs, the SPC values were integrated throughout the FlowCapt height:

$$
\mu_{\mathrm{SPCint}}=\frac{1}{H_{h}-H_{1}} \int_{H 1}^{H h} \mu_{\mathrm{SPC}}(z) d z,
$$

with $\mu_{\text {SPCint }}$ as the integrated value on the flux from the SPCs $\left(\mathrm{g} \mathrm{m}^{-2} \mathrm{~s}^{-1}\right)$ and $\mu_{\mathrm{SPC}}(z)$ as the flux at a given height estimated by the SPCs. Based on the different empirical formulations, the flux profile in the diffusion layer for aeolian snow transport event was assumed to follow a power law (Budd et al. 1966; Kobayashi 1978; Mann et al. 2000; Gordon et al. 2010; Nishimura and Nemoto 2005). This assumption came from the diffusion theory of snow drift (Radok 1977; Naaim-Bouvet et al. 2014). It is valid in the diffusion layer without precipitation. The parameters were calculated from a regression between the two lower SPCs as long as the lower SPC was always above the saltation layer (always at least $20 \mathrm{~cm}$ above the surface).

Several uncertainties arise with the integration of SPC fluxes. First, with precipitation, the flux profile was different and it may have underestimated the integrated flux by the power law. Nevertheless, the effect of the precipitation on the flux profile has been noted from 1 to $3 \mathrm{~m}$ high (Nishimura and Nemoto 2005). Thus, the underestimation, if present, would be limited to only the higher part of the profile. Second, during precipitation, measurement errors may occur. On the one hand, the SPC may overestimate the snow particle density compared to precipitating snowflake density, and so it may overestimate the integrated flux: in wind tunnel experiments, the ratio of the snow mass flux obtained by an SPC on the snow mass flux obtained by a net was 2.6 for 
dendritic particles (Sato et al. 2005). On the other hand, particles with an equivalent diameter above $500 \mu \mathrm{m}$ will have an underestimated volume (it should be remembered that if the diameter of a snow particle is greater than the maximum diameter class-i.e., $500 \mu \mathrm{m}$ - then the snow particle is considered to have a diameter of $500 \mu \mathrm{m})$, and so it may underestimate the integrated flux. The importance of each factor, which can potentially offset each other, depends on the precipitating event. With these uncertainties in mind, the SPC still had the most reliable flux value compared to other unmanned instruments and the integrated flux was used as a reference.

The SPC fluxes and the FlowCapt_1G fluxes could not be compared with the available data: during the season, the lower end of the FlowCapt_1G was nearly always in the saltation layer. The flux profile in the saltation layer (Pomeroy and Gray 1990; Sørensen 1991) differed from the profile in the diffusion layer. To apply Eq. (5), the SPC1 must always be above the saltation layer and the flux profile calculated from the SPC fluxes cannot be applied to the part of the FlowCapt_1G in the saltation layer.

To take several uncertainties into account, we determined the measurement errors associated with each sensor. For the FlowCapt, errors expressly stated by the manufacturer were $\pm 5 \%$ (Chritin et al. 1999). In the following discussion and graphs, the possible difference in height due to the local differences in surface elevation between the FlowCapt and the SPCs is taken into account in the uncertainties associated with the integrative SPC fluxes. The measurement uncertainty stated by the SPC manufacturer are not specified but are considered negligible compared to those due to the possible difference in height between the FlowCapt and the SPC. Since the flux profile is not linear with height, the error bar is not symmetrical to the measuring point.

For each case studied, the FlowCapt_2G mean error and the standard deviation of this mean error compared to the integrative SPC fluxes were calculated. The uncertainty due to the difference in surface elevation was propagated in the calculation using the Guide to the Expression of Uncertainty in Measurement (GUM method; see Eqs. (4) and (5) in Trouvilliez et al. 2014). The error due to the difference in surface elevation in the mean value of the SPC fluxes, noted $\delta \overline{\mu_{\text {SPCint }}}$, is calculated using

$$
\delta \overline{\mu_{\text {SPCint }}}=\sqrt{\frac{1}{N} \sum_{i=1}^{N} \delta \mu_{\text {SPCint } i}^{2}}
$$

with $N$ as the number of measurements and $\delta \mu_{\text {SPCint } i}$ as the error of the $i$ th integrative SPC flux. The same method can be applied to calculate the error on the standard deviation, noted $\delta \sigma\left(\mu_{\mathrm{SPCint}}\right)$, by propagating

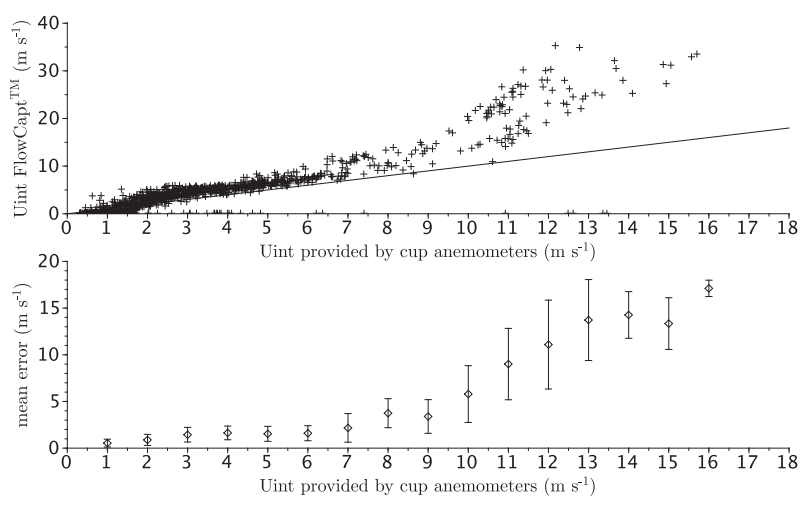

FIG. 3. (top) Integrated wind speed $\left(U_{\text {int }}\right)$ provided by the FlowCapt vs the integrated wind speed calculated from the two cup anemometers. The black line represents the 1:1 line. (bottom) Diamonds stand for the mean errors of the FlowCapt wind speeds compared to the integrated wind speeds; the vertical bars represent two standard deviations for each wind speed error.

the error of each integrative SPC flux (see annexe B of Trouvilliez 2013:

$$
\delta \sigma\left(\mu_{\text {SPCint }}\right)=\sqrt{\sum_{i=1}^{N}\left[\frac{\mu_{\text {SPCint } i}-\mu_{\text {SPCint }}}{N \sigma\left(\mu_{\text {SPCint }}\right)}\right]^{2} \delta \mu_{\text {SPCint } i}^{2}},
$$

with $\mu_{\text {SPCint } i}$ as the $i$ th integrative SPC flux; and $\sigma\left(\mu_{\text {SPCint }}\right)$ and $\overline{\mu_{\text {SPCint }}}$ as the standard deviation and the mean value of the integrative SPC fluxes, respectively. The mean relative error was also calculated with

$$
\overline{E_{\text {FlowCap_2G }}}=\sum \frac{\left|\mu_{\text {SPCint } i}-\mu_{\text {FlowCapt } i}\right|}{\mu_{\text {FlowCapti }}} \times 100,
$$

where $\overline{E_{\text {FlowCap_2G }}}$ is the mean relative error; and $\mu_{\text {SPCint } i}$ and $\mu_{\text {FlowCapt } i}$ are the $i$ th integrated snow mass flux from the SPCs and the $i$ th snow mass flux from the FlowCapt $2 \mathrm{G}$, respectively (both in $\mathrm{g} \mathrm{m}^{-2} \mathrm{~s}^{-1}$ ).

\section{Results}

\section{a. Wind speed}

The wind speed output of the FlowCapt is rarely used, and the only comparison available in the literature (Savelyev et al. 2006) shows a good correlation between FlowCapt measurements and the 1-m-high anemometer or 10-m-high anemometer outputs for wind speeds between 4 and $10 \mathrm{~m} \mathrm{~s}^{-1}$ with a 0.76 coefficient of correlation $(r)$. Here we compared the wind speed values of the FlowCapt_2G with the integrated wind speed from the two cup anemometers on a 10-min basis. The evaluation covered the period between 5 March and 11 April, when temperatures on the 10-m mast and wind speeds from the FlowCapt_2G were both available. The results are shown in Fig. 3. 
TABLE 1. Percentages of 10-min periods compared to the overall 10-min period (15 Feb-11 Apr) when: case 1, the lower SPC and FlowCapt detect a flux together; case 2, neither detects a flux; case 3, only the lower SPC detects a flux; and case 4, only the FlowCapt detects a flux.

\begin{tabular}{ccccc}
\hline FlowCapt generation & $\begin{array}{c}\text { SPC and FlowCapt flux } \\
\text { (case 1) }(\%)\end{array}$ & $\begin{array}{c}\text { No flux } \\
\text { (case 2) }(\%)\end{array}$ & $\begin{array}{c}\text { SPC alone } \\
\text { (case 3) }(\%)\end{array}$ & $\begin{array}{c}\text { FlowCapt alone } \\
(\text { case 4) }(\%)\end{array}$ \\
\hline First & 26 & 60 & 7 & 7 \\
Second & 18 & 66 & 15 & 1
\end{tabular}

On the one hand, there is a 0.91 correlation coefficient $(r)$ between the two wind speeds. This correlation is higher than from the measurements taken by Savelyev et al. (2006), possibly because an integrated wind speed on the FlowCapt length was used, whereas the previous survey used a fixed anemometer. On the other hand overestimation and increasing variability are magnified at higher wind speed: the mean error is $2.2 \mathrm{~m} \mathrm{~s}^{-1}$ with an error standard deviation of $3.2 \mathrm{~m} \mathrm{~s}^{-1}$. The FlowCapt errors depend on the wind speed (Fig. 3 ): between 2 and $9 \mathrm{~m} \mathrm{~s}^{-1}$, the mean errors range from 0.5 to $3.4 \mathrm{~m} \mathrm{~s}^{-1}$ with an error standard deviation ranging from 0.41 to $1.8 \mathrm{~m} \mathrm{~s}^{-1}$. Above $9 \mathrm{~m} \mathrm{~s}^{-1}$, the mean errors increased to $17 \mathrm{~m} \mathrm{~s}^{-1}$ with a standard deviation up to $4.8 \mathrm{~m} \mathrm{~s}^{-1}$. The correlation coefficient is only 0.39 between the two wind speeds considering only integrative wind speed above $9 \mathrm{~m} \mathrm{~s}^{-1}$.

\section{b. Event detection}

Events were detected over 56 days between 15 February and 11 April 2012, which is the longest period during the season when the SPC1 was always at least $20 \mathrm{~cm}$ above the surface, and the sensitive surface of the FlowCapt_1G was not entirely buried. No previous comparison is available in the literature for the FlowCapt in terms of snow transport detection. Every $10 \mathrm{~min}$, the mean was differentiated between four cases: both the lower SPC and the FlowCapt detect a flux (case 1); both the lower SPC and the FlowCapt do not detect a flux (case 2); only the SPC detects a flux (case 3); only the FlowCapt detects a flux (case 4). The number of measurements in each case is then divided by the total number of measurements during the season (Table 1).

The FlowCapt_1G gave similar results as the SPC1 $86 \%$ of the time (cases 1 and 2) but missed $7 \%$ of the events detected by the SPC1 (case 3) and detected a flux, whereas the SPC1 detected none in $7 \%$ of the time (case 4).

The FlowCapt_2G gave similar results as the SPC1 $84 \%$ of the time but missed drifting snow events recorded by the SPC1 $15 \%$ of the time when the lower SPC detected a flux, and there are few measurements when only the FlowCapt_2G detected a flux (1\%).

\section{c. Snow mass flux, event without precipitation: 6 February 2012}

The SPCs are able to detect snow precipitations (Sugiura et al. 2009) and to distinguish between drifting snow events with concurrent precipitation and without concurrent precipitation (Naaim-Bouvet et al. 2014). The values of drifting snow flux quantification were first compared during a drifting snow event without precipitation. The selection of the event has been done over three criteria: an event of several hours, with a constant sensor height, and with integrative SPC fluxes above $5 \mathrm{~g} \mathrm{~m}^{-2} \mathrm{~s}^{-1}$ for a couple of hours. Therefore, $12 \mathrm{~h}$ of acquisition were chosen on 6 February 2012 during which the sensor height remained constant and with a $13 \mathrm{~m} \mathrm{~s}^{-1}$ mean wind speed of $61 \mathrm{~cm}$ from the snow cover. Therefore, the snow mass flux was drawn as a function of the wind speed (Fig. 4).

The FlowCapt_2G fluxes were similar in magnitude to the results obtained by the SPCs (Fig. 5) associated with a 0.91 correlation coefficient. The mean error was $1.32 \mathrm{~g} \mathrm{~m}^{-2} \mathrm{~s}^{-1} \pm 1.06 \mathrm{~g} \mathrm{~m}^{-2} \mathrm{~s}^{-1}$, which corresponds to a relative error of $648 \%$. The dispersion of the FlowCapt_ $2 \mathrm{G}$ fluxes was estimated with an error standard deviation at $1.19 \mathrm{~g} \mathrm{~m}^{-2} \mathrm{~s}^{-1} \pm 0.13 \mathrm{~g} \mathrm{~m}^{-2} \mathrm{~s}^{-1}$. The FlowCapt_2G and the SPC values increased similarly with increasing wind speed.

Another important point is to compare the quantity of snow transported during the event, because it will have

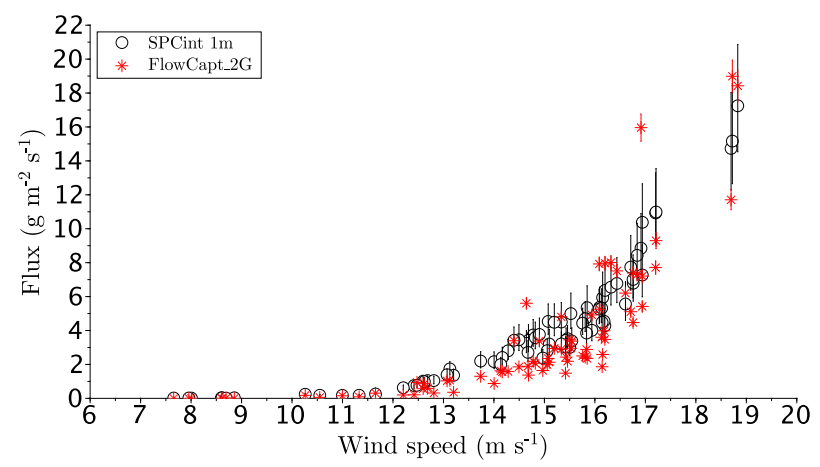

FIG. 4. Aeolian transport of snow without precipitation on $6 \mathrm{Feb}$ 2012. FlowCapt_2G fluxes and SPCint over 1-m fluxes (SPCint 1m) vs the wind speed. The vertical bars represent, for the SPC the uncertainty due to the possible difference in height between the SPCs and for the FlowCapt the uncertainty of the flux measurement. 


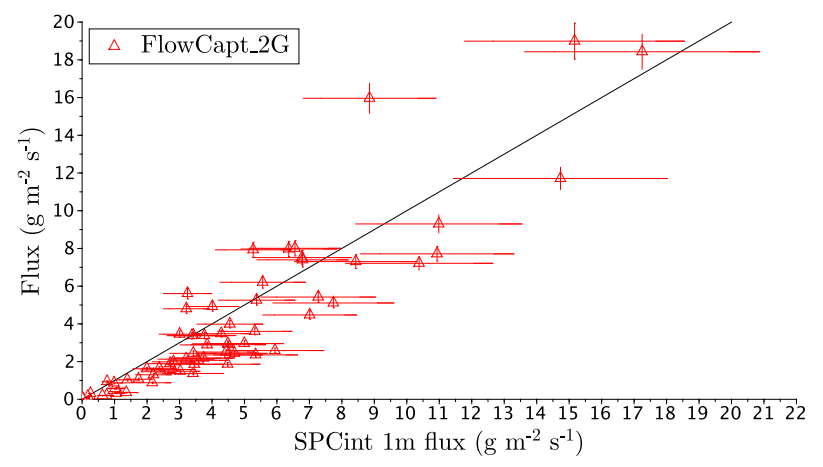

FIG. 5. Aeolian transport of snow without precipitation on 6 Feb 2012. FlowCapt_2G fluxes vs SPCint $1 \mathrm{~m}$. The horizontal bars stand for the errors in the SPC fluxes due to the possible difference in height between the SPC and the FlowCapt, and the vertical bars stand for the uncertainty in the flux measurement by the FlowCapt. The black line represents the 1:1 line.

an influence on the surface mass balance and on the snow redistribution (Fig. 6). It represents the fluxes integrated on the height $\left(\mathrm{kg} \mathrm{m}^{-1}\right)$ covered by the FlowCapt since the beginning of the event under review. The quantity of snow transported by the FlowCapt_2G was close to that of the integrative SPCs within the margin of uncertainty due to the possible sensor height variation. It seems that on this particular drifting snow episode without precipitation, the FlowCapt_2G is able to quantify the total quantity of snow transported.

\section{d. Snow mass flux, event with precipitation: 7 April 2012}

The values of snow mass flux quantification were then compared during an aeolian snow transport event with precipitation. Then the same criteria for the event without precipitation have been applied. An event lasting nearly 1 day was chosen, 7 April 2012 (Fig. 7). The wind speed, however, was lower than previously and frequently below $6 \mathrm{~m} \mathrm{~s}^{-1}$. The error bars associated with the integrative SPC fluxes linked to a possible difference in height between the FlowCapt and the SPCs were less than reported in section $5 \mathrm{c}$ because, due to the precipitation, the flux profile was more constant with height. The FlowCapt_2G underestimated the results obtained by the SPC, except in one case. The mean error is lower than the previous event studied with $0.91 \pm$ $0.21 \mathrm{~g} \mathrm{~m}^{-2} \mathrm{~s}^{-1}$, which corresponds to a relative error of $379 \%$, due to lower fluxes recorded on the event, and the correlation coefficient is lower with $r=0.70$ (Table 2).

The quantity of snow transported obtained with the different sensors was also compared for this event with concomitant precipitation (Fig. 8). In this event, the FlowCapt_2G underestimated the total quantity of snow transported by a factor of 3 .

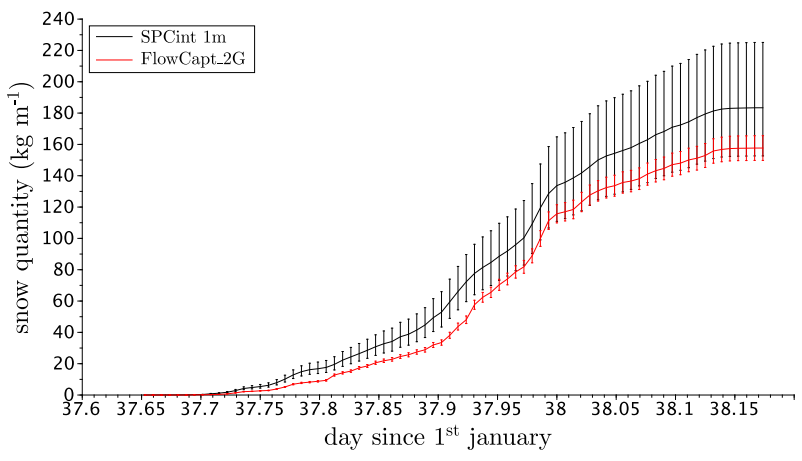

FIG. 6. The quantity of snow transported (snow quantity) from the beginning of the event without precipitation on 6 Feb. FlowCapt_2G with the manufacturer's calibration and SPCint $1 \mathrm{~m}$. The vertical bars represent, for the SPC the uncertainty due to the possible difference in height between the SPC and the FlowCapt, and for the FlowCapt the uncertainty of the sensor on the snow quantity measurement.

\section{e. Snow mass flux, the entire season}

The season encompassed different meteorological situations with a broader range of snow fluxes than shown by the 6 February and 7 April events. To evaluate FlowCapt_2G fluxes in more general conditions, the entire season was considered. Each 10-min period was distinguished between two cases: 10-min periods with snowfall and 10-min periods without snowfall. Determination of precipitation periods from the SPCs is problematic over the entire season and another method is used. The international reference standard to estimate snowfall is the double fence intercomparison reference (Goodison et al. 1998). As previously highlighted in Naaim-Bouvet et al. (2014), this approach could be advantageous and is necessary for further investigation, but even in this case, aeolian snow transport could affect

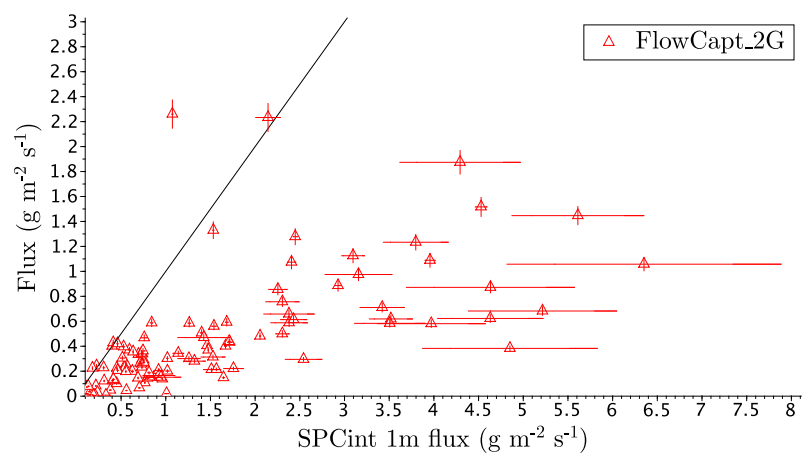

FIG. 7. Horizontal snow fluxes from an aeolian transport of snow with precipitation on 7 Apr 2012. FlowCapt_2G and SPCint 1m fluxes. The horizontal bars stand for the errors in the SPC fluxes due to the possible difference in height between the SPC and the FlowCapt, and the vertical bars stand for the uncertainty in the flux measurement by the FlowCapt. The black line represents the 1:1 line. 
TABLE 2. Correlation coefficient, mean error, standard deviation and relative error, with uncertainties of the FluxCapt_2G fluxes compared to SPCint fluxes for the event without precipitation, with precipitation, and for the period between 15 Feb and 11 Apr (entire season). Total quantities of snow transported with the uncertainty range are presented in the last two columns for SPCint $1 \mathrm{~m}$ and for FlowCapt_2G.

\begin{tabular}{lcccccc}
\hline \hline \multicolumn{1}{c}{ Event considered } & $\begin{array}{c}\text { Correlation } \\
\text { coefficient }\end{array}$ & $\begin{array}{c}\text { Mean error } \\
\left(\mathrm{g} \mathrm{m}^{-2} \mathrm{~s}^{-1}\right)\end{array}$ & $\begin{array}{c}\text { Std dev } \\
\left(\mathrm{g} \mathrm{m}^{-2} \mathrm{~s}^{-1}\right)\end{array}$ & $\begin{array}{c}\text { Relative } \\
\text { error }(\%)\end{array}$ & $\begin{array}{c}\text { Snow transported } \\
\text { SPCint 1m }\left(\mathrm{kg} \mathrm{m}^{-1}\right)\end{array}$ & $\begin{array}{c}\text { Snow transported } \\
\text { FlowCapt_2G (kg m }\end{array}$ \\
\hline Event without precipitation & 0.91 & $1.23 \pm 1.06$ & $1.19 \pm 0.13$ & 648 & $183(225-153)$ & $158(166-150)$ \\
Event with precipitation & 0.70 & $0.91 \pm 0.21$ & $1.10 \pm 0.04$ & 379 & $96(103-92)$ & $29(30-28)$ \\
Entire season & 0.80 & $3.58 \pm 3.00$ & $15.62 \pm 0.33$ & 907 & $4655(4012-5646)$ & $793(754-833)$ \\
Entire season for flux $<20 \mathrm{~g} \mathrm{~m}^{-2} \mathrm{~s}^{-1}$ & 0.42 & $0.93 \pm 0.62$ & $2.15 \pm 0.04$ & 895 & $3456(2986-4159)$ & $367(348-385)$ \\
Entire season for flux $>20 \mathrm{~g} \mathrm{~m}^{-2} \mathrm{~s}^{-1}$ & 0.87 & $66.87 \pm 14.70$ & $46.64 \pm 1.55$ & 1080 & $1199(1025-1486)$ & $427(405-447)$ \\
\hline
\end{tabular}

the measurement of true precipitation. Therefore, we chose an indirect estimation of solid precipitation: Système d'analyse fournissant des renseignements atmosphériques à la neige (SAFRAN) modeling (Durand et al. 1993) provides a set of calculated meteorological parameters, including precipitation, that are considered relevant for the forecast of avalanche hazard in mountainous regions using all the data available around these analysis points. SAFRAN has been widely validated and used in the field of snow and avalanche research (Durand et al. 1999; Naaim et al. 2013). In the Grandes Rousses range, where the Lac Blanc Pass is located, SAFRAN uses precipitation from six wind-sheltered stations covering the elevation range of $730-2350 \mathrm{~m}$.

The FlowCapt fluxes were compared to the SPC fluxes over the period between 15 February and 11 April, which corresponds to the longest uninterrupted period when the SPC1 was at least $20 \mathrm{~cm}$ above the snow cover, with the addition of the first event studied (Fig. 9). The SPC1 height varied from 0.2 to $0.4 \mathrm{~m}$.

On the one hand, Fig. 9 shows that for fluxes lower than $20 \mathrm{~g} \mathrm{~m}^{-2} \mathrm{~s}^{-1}$, the FlowCapt_2G mainly underestimated the fluxes but overestimations were present. The correlation coefficient is 0.42 , associated with a mean error of $0.93 \pm 0.62 \mathrm{~g} \mathrm{~m}^{-2} \mathrm{~s}^{-1}$, which corresponds to a relative error of $895 \%$ (Table 2). On the other hand, for SPC fluxes above $20 \mathrm{~g} \mathrm{~m}^{-2} \mathrm{~s}^{-1}$, the FlowCapt_2G always underestimated the fluxes (Fig. 9). The correlation coefficient is higher with 0.87 , associated with a mean error of $66.87 \pm 14.70 \mathrm{~g} \mathrm{~m}^{-2} \mathrm{~s}^{-1}$, which corresponds to a relative error of $1080 \%$. If all data are compared, there is a 0.80 correlation coefficient and the mean error is $3.58 \mathrm{~g} \mathrm{~m}^{-2} \mathrm{~s}^{-1} \pm 3.00 \mathrm{~g} \mathrm{~m}^{-2} \mathrm{~s}^{-1}$, which represents a relative error of $908 \%$. The underestimation is nearly general and the higher fluxes (above $20 \mathrm{~g} \mathrm{~m}^{-2} \mathrm{~s}^{-1}$ ) are associated with the higher SPC fluxes. A linear regression between the SPC fluxes above $20 \mathrm{~g} \mathrm{~m}^{-2} \mathrm{~s}^{-1}$ and the FlowCapt_2G fluxes gave a slope coefficient of 0.12 , with a coefficient of determination of 0.76 (Fig. 9).

As previously noted, the FlowCapt_2G fluxes recorded with a concomitant snowfall were always underestimated compared to the SPC fluxes, except for one point during the 7 April event. For the FlowCapt_2G fluxes without concomitant snowfall, the fluxes may be close to the SPC fluxes, as noted for the 6 February event, but they may also have the same underestimation as the FlowCapt_ $2 \mathrm{G}$ fluxes with snowfall or present an overestimation for SPC fluxes below $2 \mathrm{~g} \mathrm{~m}^{-2} \mathrm{~s}^{-1}$ (Fig. 9).

The general underestimation is also detected on the total quantity of snow transported during the winter season (Table 2): the FlowCapt_2G recorded a value equal to $20 \%$ of the SPC value. The value of the quantity of snow transported depends on the ratio between small and intense transport events during the season: the higher the fluxes, the higher the FlowCapt_2G underestimation of the quantity of snow transported.

\section{Discussion and concluding remarks}

Several instruments exist to detect and quantify the aeolian transport of snow in remote conditions. No standard measurements exist and the sensors were compared. The acoustic FlowCapt sensors were compared to the snow particle counter S7 optical sensor,

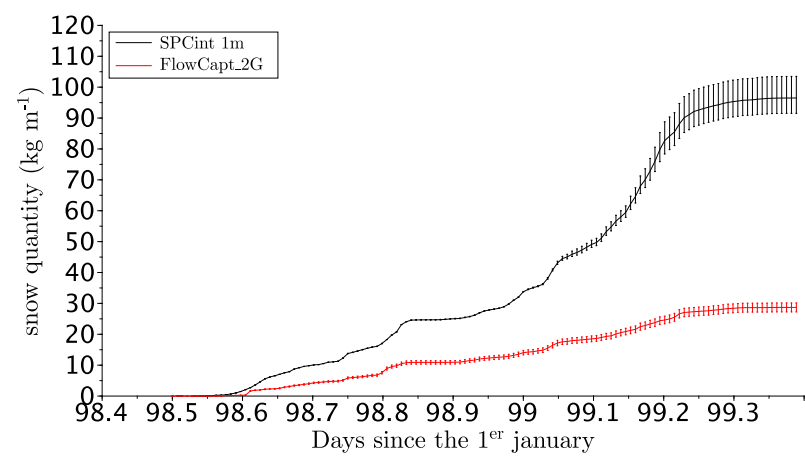

FIG. 8. The quantity of snow transported (snow quantity) from the beginning of the event with precipitation on 7 Apr. FlowCapt $2 \mathrm{G}$ and the SPCint $1 \mathrm{~m}$. The vertical bars represent, for the SPC the uncertainty due to the possible difference in height between the SPC and the FlowCapt, and for the FlowCapt the uncertainty of the sensor on the snow quantity measurement. 

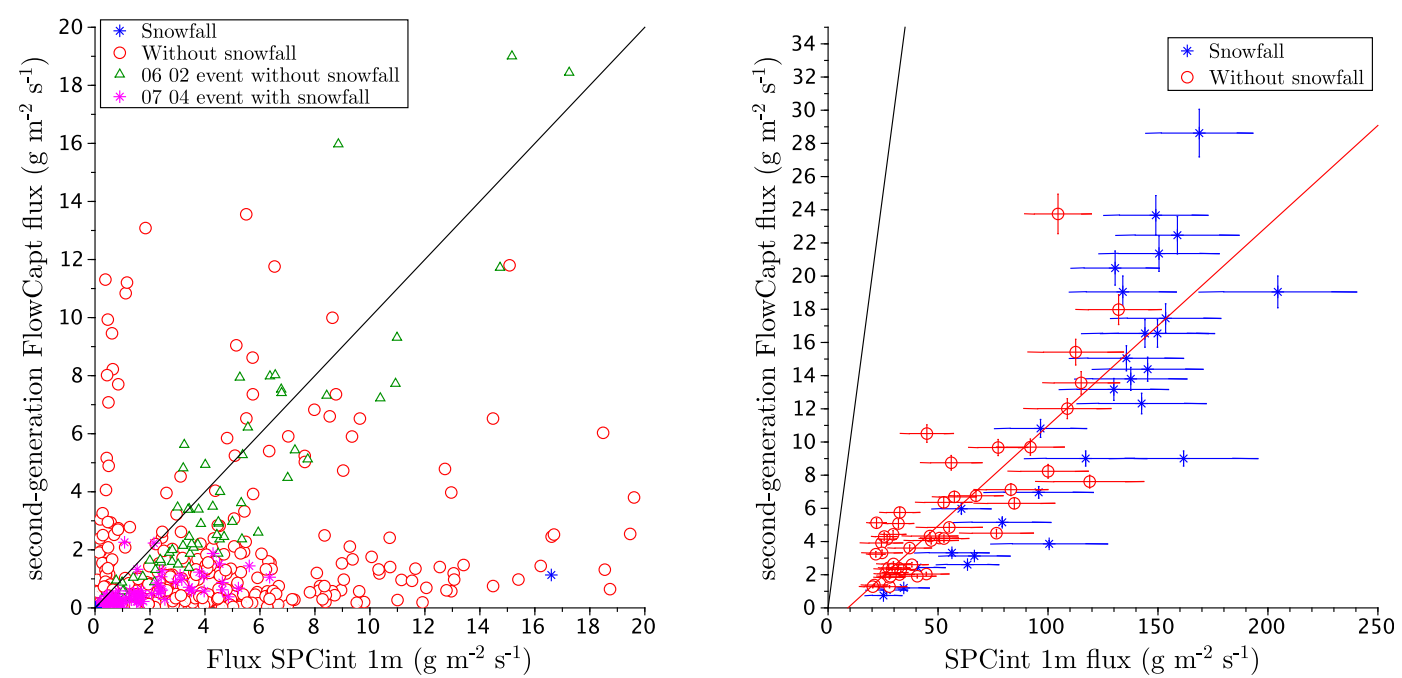

FIG. 9. Horizontal snow fluxes between $15 \mathrm{Feb}$ and $11 \mathrm{Apr}$, with the addition of the 6 February event. FlowCapt_ $2 \mathrm{G}$ fluxes vs SPCint $1 \mathrm{~m}$ fluxes. The fluxes are distinguished according to the presence of snowfall (snowfall) or absence (without snowfall): integrative SPC fluxes (left) below 20 and (right) above $20 \mathrm{~g} \mathrm{~m}^{-2} \mathrm{~s}^{-1}$. The horizontal bars stand for the errors in the SPC fluxes due to the possible difference in height between the SPC and the FlowCapt, and the vertical bars stand for the uncertainty on the flux measurement by the FlowCapt. These bars are not represented in the left panel to preserve the figure's readability. The fluxes from the two events analyzed, 6 Feb (06 02) and 7 Apr (07 04), are highlighted. The black lines represent the 1:1 line, and the red line in the right panel stands for the regression line on all values (with and without snowfall).

considered here as the reference, in the French Alps at the Lac Blanc Pass, where a bench test for the aeolian transport of snow is set up. Two generations of FlowCapt were tested and compared. To our knowledge, the second-generation FlowCapt was evaluated here for the first time.

\section{a. Wind speed}

The FlowCapt_2G wind speed behavior changes around an integrative wind speed of $9 \mathrm{~m} \mathrm{~s}^{-1}$ with a greater error and error dispersion above this speed. The FlowCapt deduced the wind speed from the acoustic pressure generated by the wind. The eddies after an obstacle, which are responsible for the acoustic pressure, vary with the Reynolds number (Williamson 1996). The Reynolds number associated with a $9 \mathrm{~m} \mathrm{~s}^{-1}$ wind speed is 18000 , which corresponds to a high variation of the base suction coefficient from the measurements of (see Fig. 10 of Artana et al. 2003). This variation may explain the behavior change in the FlowCapt for wind. Because the correlation with real anemometers is low and inconstant, FlowCapt_2G can only provide broad estimates of wind speed and are useless for quantitative meteorological applications.

\section{b. Event detection}

For the FlowCapt_1G, the events detected only by the FlowCapt may be explained by the difference in height between the two instruments: the SPC1 was always higher than the FlowCapt_1G during the evaluation period and the FlowCapt_1G perceived events very close to the surface, which the SPC1 could not detect. The height difference cannot explain the opposite case ( $7 \%$ of the time) when the FlowCapt_1G missed an event. This may have been due to less sensitive event detection than the SPC1.

For the FlowCapt_2G, the difference in detection may also be explained by the difference in height between the two sensors due to the presence of sastrugi. As previously noted, the sensitive surface of the FlowCapt was positioned $\pm 8 \mathrm{~cm}$ from the SPC1; the SPC1 may be lower than the FlowCapt_2G and therefore may have detected events that the FlowCapt_2G missed and vice versa: the beginning of the sensitive surface of the FlowCapt_2G may be lower than the SPC1 and therefore may have detected events that the SPC1 missed.

The first- and second-generation FlowCapt may also have been less sensitive to event detection than the SPC1, which may explain the missing events by the first- and second-generation devices. To evaluate the sensitivity of both generations, the detection threshold chosen for the SPC1 was increased from 0.001 to $1 \mathrm{~g} \mathrm{~m}^{-2} \mathrm{~s}^{-1}$ to focus on more significant aeolian snow transport events. In this case, the FlowCapt_1G detected a flux $99.9 \%$ of the time during which the SPC1 detected a flux. For the FlowCapt_2G, this percentage was $98.6 \%$. These percentages rise to $100 \%$ for the first- and second-generation devices if the SPC1 flux threshold is raised to $10 \mathrm{~g} \mathrm{~m}^{-2} \mathrm{~s}^{-1}$. 
Overall, the first- and second-generation FlowCapts seem to be good aeolian snow transport event detectors, especially for significant events. Furthermore, the FlowCapt may be set up very close to the ground, or even half-buried, and may detect the very initial start of the transport event or an event very close to the ground. They are robust enough to withstand the polar environment for several years and are low power consuming. They are an advantageous alternative to the detection of aeolian snow transport events in remote locations (Trouvilliez et al. 2014).

\section{c. Snow mass flux quantification}

The comparison was made only with the FlowCapt_ $2 \mathrm{G}$. The FlowCapt is a sensor based on the particle's momentum, that is, the particle speed and density. The study of the 6 February event without snowfall and 7 April with snowfall suggests a difference in the FlowCapt_2G behavior depending on the presence or absence of snowfall: a satisfactory behavior of the FlowCapt_2G in the absence of snowfall and a flux underestimation of the snow mass fluxes in the presence of snowfall. This difference may be explained by two factors. First, the SPC tends to overestimate aeolian snow mass fluxes for dendritic particles (Sato et al. 2005). Second, the FlowCapt calibration [Eq. (1)] depends on the particle type (more precisely the particle density) and speed, as previously highlighted by Cierco et al. (2007). During an aeolian snow transport with snowfall, the particles are more generally dendritic at Lac Blanc Pass than for events without snowfall that have more round grains (Guyomarc'h and Mérindol 1998). Thus, the particle density should be lower for events with snowfall than without and the FlowCapt_ $2 \mathrm{G}$ behavior should not be the same.

However, this trend is not reproducible throughout the winter season (15 February-11 April). For integrative SPC fluxes (SPCint) below $20 \mathrm{~g} \mathrm{~m}^{-2} \mathrm{~s}^{-1}$, the FlowCapt_2G snow mass fluxes recorded with snowfall are underestimated, whereas the fluxes recorded without snowfall may be over- and underestimated. For SPCint above $20 \mathrm{~g} \mathrm{~m}^{-2} \mathrm{~s}^{-1}$, the FlowCapt_2G behavior change observed is no longer visible. The wind speed was higher during the 6 February event than for the 7 April event. The same observation was made for the SPCint fluxes above $20 \mathrm{~g} \mathrm{~m}^{-2} \mathrm{~s}^{-1}$, with a mean wind speed of $15 \mathrm{~m} \mathrm{~s}^{-1}$, as for the SPCint fluxes below $20 \mathrm{~g} \mathrm{~m}^{-2} \mathrm{~s}^{-1}$, with a mean wind speed of $6 \mathrm{~m} \mathrm{~s}^{-1}$. Thus, the particle speed should have the greatest influence on the FlowCapt_2G flux response. Moreover, the dendritic particles are more likely to turn into round grains at higher wind speeds. Nevertheless, only four events have SPCint fluxes above $20 \mathrm{~g} \mathrm{~m}^{-2} \mathrm{~s}^{-1}$ and additional data are necessary to better characterize the higher second-generation FlowCapt fluxes.

The particle speed and density, which vary from one aeolian snow transport event to another, play a key role in the flux estimation by the FlowCapt, and the results of an intercomparison depend on a large extent on these factors. Thus, it is important to know that the FlowCapt_2G can record an underestimation of the quantity of snow transported at one location: over the entire season, the quantity of snow transported recorded by the SPC is between 4 and 6 times greater than the quantity recorded by FlowCapt_2G.

The second-generation instrument presents a general improvement compared to the first-generation device (Naaim-Bouvet et al. 2010; Cierco et al. 2007). The second generation was improved in terms of hardware conception and an individual calibration. A thirdgeneration should soon be made available with improved hardware and numerical processing (V. Chritin 2015, personal communication). This third-generation instrument has yet to be evaluated.

A more detailed investigation should be conducted to investigate the second-generation instrument's response when the tube is partially buried. Indeed, FlowCapt installed on remote stations with high snow height variations are frequently partially buried (Trouvilliez et al. 2014). The particle speed should be evaluated on the sensor's response, as it has an influence. Furthermore, snow grain types vary from one episode to another and from one site to another (Guyomarc'h and Mérindol 1998). The influence of the different snow grain types should also be evaluated on the sensor's response. The bench installed at Lac Blanc Pass, with different sensors to measure the aeolian transport of snow, is a valuable tool that may be used to compare with other transport sensors.

Acknowledgments. This comparison would not have been possible without the financial support of the European FP-7 ICE2SEA, ALCOTRA INTERREG MAP3 program. INSU (Program LEFE-CLAPA) also contributed financially to this study. Vincent Vionnet from CNRM/CEN Météo-France is acknowledged for providing the SAFRAN data.

\section{REFERENCES}

Artana, G., R. Sosa, E. Moreau, and G. Touchard, 2003: Control of the near-wake flow around a circular cylinder with electrohydrodynamic actuators. Exp. Fluids, 35, 580-588, doi:10.1007/ s00348-003-0704-z.

Barchyn, T. E., C. H. Hugenholtz, and J. T. Ellis, 2011: A call for standardization of aeolian process measurements: Moving beyond relative case studies. Earth Surf. Processes Landforms, 36, 702-705, doi:10.1002/esp.2136.

Bellot, H., A. Trouvilliez, F. Naaim-Bouvet, C. Genthon, and H. Gallée, 2011: Present weather-sensor tests for measuring 
drifting snow. Ann. Glaciol., 52, 176-184, doi:10.3189/ 172756411797252356.

Budd, W. F., W. R. J. Dingle, and U. Radok, 1966: The Byrd snow drift project outline and basic results. Studies in Antarctic Meteorology, M. J. Rubin, Ed., Antarctic Research Series, Vol. 9, Amer. Geophys. Union, 71-134.

Chritin, V., R. Bolognesi, and H. Gubler, 1999: FlowCapt: A new acoustic sensor to measure snowdrift and wind velocity for avalanche forecasting. Cold Reg. Sci. Technol., 30, 125-133, doi:10.1016/S0165-232X(99)00012-9.

Cierco, F.-X., F. Naaim-Bouvet, and H. Bellot, 2007: Acoustic sensors for snowdrift measurements: How should they be used for research purposes? Cold Reg. Sci. Technol., 49, 74-87, doi:10.1016/j.coldregions.2007.01.002.

Durand, Y., É. Brun, L. Mérindol, G. Guyomarc'h, B. Lesaffre, and É. Martin, 1993: A meteorological estimation of relevant parameters for snow models. Ann. Glaciol., 18, 65-71.

—_, G. Giraud, É. Brun, L. Mérindol, and É. Martin, 1999: A computer-based system simulating snowpack structures as a tool for regional avalanche forecasting. J. Glaciol., 45, 469-484.

Gallée, H., A. Trouvilliez, C. Agosta, C. Genthon, V. Favier, and F. Naaim-Bouvet, 2013: Transport of snow by the wind: A comparison between observations in Adélie Land, Antarctica, and simulations made with the regional climate model MAR. Bound.Layer Meteor., 146, 133-147, doi:10.1007/s10546-012-9764-z.

Garratt, J. R., 1992: The Atmospheric Boundary Layer. Cambridge Atmospheric and Space Science Series, Cambridge University Press, 316 pp.

Goodison, B. E., P. Y. T. Louie, and D. Yang, 1998: The WMO solid precipitation measurement intercomparison. Final Rep., WMO Instruments Observing Methods Rep. 67, WMO/TD872, 212 pp.

Gordon, M., S. Biswas, P. A. Taylor, J. Hanesiak, M. AlbarranMelzer, and S. Fargey, 2010: Measurements of drifting and blowing snow at Iqaluit, Nunavut, Canada during the star project. Atmos.-Ocean, 48, 81-100, doi:10.3137/AO1105.2010.

Guyomarc'h, G., and L. Mérindol, 1998: Validation of an application for forecasting blowing snow. Ann. Glaciol., 26, 138-143.

Jaedicke, C., 2001: Acoustic snowdrift measurements: Experiences from the FlowCapt instrument. Cold Reg. Sci. Technol., 32, 71-81, doi:10.1016/S0165-232X(01)00017-9.

- 2002: Snow drift losses from an Arctic catchment on Spitsbergen: An additional process in the water balance. Cold Reg. Sci. Technol., 34, 1-10, doi:10.1016/S0165-232X(01)00041-6.

Kobayashi, S., 1978: Snow transport by katabatic winds in Mizuho Camp area, East Antarctica. J. Meteor. Soc. Japan, 56, 130-139.

Lehning, M., and C. Fierz, 2008: Assessment of snow transport in avalanche terrain. Cold Reg. Sci. Technol., 51, 240-252, doi:10.1016/j.coldregions.2007.05.012.

_ , and Coauthors, 2002: Snow drift: Acoustic sensors for avalanche warning and research. Nat. Hazards Earth Syst. Sci., 2, 121-128, doi:10.5194/nhess-2-121-2002.

Lenaerts, J. T. M., M. R. Van Den Broeke, W. J. van de Berg, E. van Meijgaard, and P. Kuipers Munneke, 2012: A new, high-resolution surface mass balance map of Antarctica (1979-2010) based on regional atmospheric climate modeling. Geophys. Res. Lett., 39, L04501, doi:10.1029/2011GL050713.

Mann, G. W., P. S. Anderson, and S. D. Mobbs, 2000: Profile measurements of blowing snow at Halley, Antarctica. J. Geophys. Res., 105, 24 491-24 508, doi:10.1029/2000JD900247.

Michaux, J.-L., F. Naaim-Bouvet, and M. Naaim, 2001: Driftingsnow studies over an instrumented mountainous site: II.
Measurements and numerical model at small scale. Ann. Glaciol., 32, 175-181, doi:10.3189/172756401781819364.

Naaim, M., Y. Durand, N. Eckert, and G. Chambon, 2013: Dense avalanche friction coefficients: Influence of physical properties of snow. J. Glaciol., 59, 771-782, doi:10.3189/2013JoG12J205.

Naaim-Bouvet, F., H. Bellot, and M. Naaim, 2010: Back analysis of drifting-snow measurements over an instrumented mountainous site. Ann. Glaciol., 51, 207-217, doi:10.3189/172756410791386661.

, - _ K. Nishimura, C. Genthon, C. Palerme, G. Guyomarc'h, and V. Vionnet, 2014: Detection of snow fall occurrence during blowing snow events using photoelectric sensors. Cold Reg. Sci. Technol., 106-107, 11-21, doi:10.1016/j.coldregions.2014.05.005.

Nishimura, K., and M. Nemoto, 2005: Blowing snow at Mizuho station, Antarctica. Philos. Trans. Roy. Soc. London, A363, 1647-1662, doi:10.1098/rsta.2005.1599.

Pomeroy, J. W., and D. M. Gray, 1990: Saltation of snow. Water Resour. Res., 26, 1583-1594, doi:10.1029/WR026i007p01583.

Radok, U., 1977: Snow drift. J. Glaciol., 19, 123-139.

Sato, T., T. Kimura, T. Ishimaru, and T. Maruyama, 1993: Field test of a new snow-particle counter (SPC) system. Ann. Glaciol., 18, 149-154. , S. Mochizuki, K. Kosugi, and M. Nemoto, 2005: Effects of particle shape on mass flux measurement of drifting snow by snow particle counter. J. Japan Soc. Snow Ice, 67, 493-502, doi:10.5331/seppyo.67.493.

Savelyev, S. A., M. Gordon, J. Hanesiak, T. Papakyriakou, and P. a. Taylor, 2006: Blowing snow studies in the Canadian Arctic Shelf Exchange Study, 2003-04. Hydrol. Processes, 20, 817827, doi:10.1002/hyp.6118.

Scarchilli, C., M. Frezzotti, P. Grigioni, L. De Silvestri, L. Agnoletto, and S. Dolci, 2010: Extraordinary blowing snow transport events in East Antarctica. Climate Dyn., 34, 11951206, doi:10.1007/s00382-009-0601-0.

Sørensen, M., 1991: An analytic model of wind-blown sand transport. Aeolian Grain Transport 1: Mechanics, O. BarndorffNielsen and B. Willetts, Eds., Acta Mechanica Supplementum, Vol. 1, Springer Vienna, 67-81.

Stull, R. B., 1988: An Introduction to Boundary Layer Meteorology. Kluwer Academic, 666 pp.

Sugiura, K., T. Ohata, D. Yang, T. Sato, and A. Sato, 2009: Application of a snow particle counter to solid precipitation measurements under Arctic conditions. Cold Reg. Sci. Technol., 58, 77-83, doi:10.1016/j.coldregions.2009.03.010.

Takeuchi, M., 1980: Vertical profile and horizontal increase of drift-snow transport. J. Glaciol., 26, 481-492.

Trouvilliez, A., 2013: Observations and Modeling of Blowing Snow in Antarctica (in French). Ph.D. dissertation, University of Grenoble, 162 pp.

- and Coauthors, 2014: A novel experimental study of aeolian snow transport in Adelie Land (Antarctica). Cold Reg. Sci. Technol., 108, 125-138, doi:10.1016/j.coldregions.2014.09.005.

Tüg, H., 1988: A pulse-counting technique for the measurement of drifting snow. Ann. Glaciol., 11, 184-186.

Vionnet, V., G. Guyomarc'h, F. Naaim-Bouvet, É. Martin, Y. Durand, H. Bellot, C. Bel, and P. Puglièse, 2013: Occurrence of blowing snow events at an alpine site over a 10-year period: Observations and modelling. Adv. Water Resour., 55, 53-63, doi:10.1016/j.advwatres.2012.05.004.

Wendler, G., 1989: Measuring blowing snow with a photo-electric particle counter at Pole Station, Antarctica. Polarforschung, 59, 9-16.

Williamson, C. H. K., 1996: Vortex dynamics in the cylinder wake. Annu. Rev. Fluid Mech., 28, 477-539, doi:10.1146/ annurev.fl.28.010196.002401. 